\title{
MicroRNA-191 targets CCAAT/enhanced binding protein $\beta$ and functions as an oncogenic molecule in human non-small cell lung carcinoma cells
}

\author{
FULIANG LI ${ }^{1}$, JINGJING WEN ${ }^{2}$, JINSHENG SHI ${ }^{2}$, YUN WANG ${ }^{1}$, FEIFEI YANG ${ }^{1}$ and CHUNYING LIU ${ }^{3}$ \\ ${ }^{1}$ Department of Pathology, Anqiu People's Hospital, Anqiu, Shandong 262100; ${ }^{2}$ Department of Pathology, \\ Weifang Yidu Central Hospital, Weifang, Shandong 262500; ${ }^{3}$ Department of B-ultrasound, \\ Anqiu People's Hospital, Anqiu, Shandong 262100, P.R. China
}

Received November 28, 2017; Accepted October 26, 2018

DOI: $10.3892 /$ etm.2019.7668

\begin{abstract}
The aberrant expression of microRNAs (miRs) may be involved in tumor growth and progression in human non-small cell lung carcinoma (NSCLC). The present study aimed to investigate the potential roles of miR-191 in NSCLC. Western blotting and reverse transcription-quantitative polymerase chain reaction were performed to assess protein and/or mRNA levels. Scratch wound healing and transwell assays were performed to determine the NSCLC cell migration and invasion. A luciferase demonstrated that CCAAT/enhanced binding protein $\beta(C / E B P \beta)$ was a target of miR-191. Previously, miR-191 has been reported to act as an oncogenic player in multiple human cancers. C/EBP $\beta$ has been identified as a target gene of miR-191; however, the roles and underlying mechanisms of miR-191 associated with the regulation of tumor invasion in NSCLC remain unknown. In the present study, it was demonstrated that miR-191 expression levels were higher in human NSCLC tumors compared with in normal adjacent tissue and elevated miR-191 expression levels were closely associated with tumor node metastasis stage in patients with NSCLC. Furthermore, transfection with miR-191 mimic inhibited C/EBP $\beta$ expression at the mRNA and protein levels and promoted A549 cell migration and invasion. $\mathrm{C} / \mathrm{EBP} \beta$ was reported to be the direct target gene of miR-191 using a dual luciferase reporter assay. Finally, C/EBP $\beta$ siRNA can mimic the effects of miR-191. These findings indicated that miR-191 may function as an oncogene in NSCLC, at least partially due to its negative regulatory on $\mathrm{C} / \mathrm{EBP} \beta$.
\end{abstract}

Correspondence to: Mrs. Chunying Liu, Department of B-ultrasound, Anqiu People's Hospital, 246 Jiankang Road, Anqiu, Shandong 262100, P.R. China

E-mail: dr_chunyingliu@outlook.com

Key words: microRNA-191, non-small cell lung carcinoma, CCAAT/enhanced binding protein $\beta$, metastasis, negative regulation

\section{Introduction}

Lung cancer has been reported to be the leading cause of cancer-associated death (1). Non-small cell lung carcinoma (NSCLC), with a 5-year survival rate of only $11 \%$, accounts for $\sim 80 \%$ of cases of lung cancer (2). The majority of cases of mortality due to cancer are caused by tumor invasion and metastasis, which have been acknowledged as the major reasons for disease progression and therapy failure (3). Therefore, the inhibition of tumor metastasis may be an important anti-cancer strategy.

MicroRNAs (miRNAs or miRs) are a group of small non-coding RNAs (18-22 nucleotides), which can regulate the expression of target mRNAs by binding to their 3'-untranslated region (UTR) (4). miRNAs are associated with a variety of cellular functions, including proliferation, apoptosis, differentiation and migration (5). miRNAs have emerged as important gene regulatory molecules in various cancers, functioning either as tumor suppressors or oncogenes; their aberrant expression and dysregulation are closely associated with the progression of cancer $(6,7)$. These functional miRNAs may be ideal diagnostic biomarkers and therapeutic targets for cancers. Among these functional miRNAs, miR-191 was reported to be notably upregulated and acted as an oncogenic member in breast (8), gastric (9) and pancreatic cancers (10), hepatocellular carcinoma (HCC) (11), colorectal carcinoma (CRC) (12), and intrahepatic cholangiocarcinoma (ICC) (13). The oncogenic effects of enhanced miR-191 expression levels are exerted on a number of cancer-specific signaling pathways. For example, the signal cascades, including miR-191-Ten-eleven translocation (TET) methylcytosine dioxygenase 1a-p53 and miR-191-ubiquitin-specific peptidase 10-p53 were identified as pivotal pathways that promote the invasion and progression of ICC and pancreatic cancer, respectively $(10,13)$. Increased miRNA-191 expression levels induced the invasion and migration of CRC cell lines via the downregulation of tissue inhibitor of metalloproteinase 3 (TIMP3), thus upregulating its downstream gene, matrix metalloproteinase 3 (12). TIMP3 was also identified as a target gene regulated by miR-191 in HCC cell lines (14). Despite advances in understanding the oncogenic roles of 
miR-191 in various human cancers, the role of miR-191 in NSCLC requires further investigation.

CCAAT/enhanced binding protein $\beta(\mathrm{C} / \mathrm{EBP} \beta)$, a member of $\mathrm{C} / \mathrm{EBP}$ family of transcription factors, serves a critical role in the modulation of cell growth and development $(15,16)$. The roles of $\mathrm{C} / \mathrm{EBP}$ in various cancers, including NSCLC, have been discussed previously $(17,18)$. Some evidence suggests that $\mathrm{C} / \mathrm{EBP} \beta$ may act as a key factor for cancer development; however, its role is reportedly controversial: Although $\mathrm{C} / \mathrm{EBP} \beta$ has been observed to be upregulated and to act as an oncogene in CRC (19), ovarian (20) and prostate cancers (21), as well as glioma (22), it has also been demonstrated to act as a tumor suppressor by inhibiting tumor migration in breast cancer $(23,24)$ and HCC $(25)$.

Given the pivotal roles of miR-191 in tumor progression, it was speculated that miR-191 may be associated with NSCLC invasion and metastasis. In the present study, the expression of miR-191 in HSCLC tissues was investigated; the overexpression of miR-191 was demonstrated to induce the migration and invasion of the A549 NSCLC cell line. Bioinformatic prediction and luciferase reporter assays suggested that $\mathrm{C} / \mathrm{EBP} \beta$ was a direct target of miR-191. The present results indicated that miR-191 may act as a potent promoter of tumorigenesis in NSCLC possibly through the negative regulation of $\mathrm{C} / \mathrm{EBP} \beta$, which may suggest a novel mechanism and provide a basis for the diagnosis and therapy for NSCLC patients.

\section{Materials and methods}

Patient samples. Tumor samples and their corresponding adjacent tissues were collected from 30 patients (age range, 32-71 years) with NSCLC admitted to Anqiu People's Hospital (Anqiu, China) between April 2016 and March 2017. These clinical samples were frozen immediately in liquid nitrogen and stored at $-80^{\circ} \mathrm{C}$ until use. Patients were included in the present study if they had not received chemotherapy or radiotherapy prior to recruitment. Details on the patients' characteristics, including gender, age, grade and stage are presented in Table I. Written informed consent was obtained from all patients and all study protocols were approved by the local ethics committee of Anqiu People's Hospital (Anqiu, China).

Cell culture. The human NSCLC cell line A549 and human embryonic kidney cells $293 \mathrm{~T}$ were purchased from the Shanghai Cell Bank, Chinese Academy of Sciences (Shanghai, China). Cells were cultured in RPMI-1640 medium (Invitrogen; Thermo Fisher Scientific, Inc., Waltham, MA, USA), supplemented with $10 \%$ fetal bovine serum (Invitrogen; Thermo Fisher Scientific, Inc.), $100 \mathrm{IU} / \mathrm{ml}$ penicillin and $100 \mathrm{mg} / \mathrm{ml}$ streptomycin (Invitrogen; Thermo Fisher Scientific, Inc.), and incubated at $37^{\circ} \mathrm{C}$ in a humidified atmosphere of $5 \% \mathrm{CO}_{2}$. Cells were passaged at $90 \%$ confluence with $0.25 \%$ Trypsin-EDTA.

miR-191 transfection. Using the transfection reagent Lipofectamine 2000 (Invitrogen; Thermo Fisher Scientific, Inc.) following the manufacturer's protocol, A549 cells were transiently transfected with $50 \mathrm{nM}$ miR-191 mimic, $50 \mathrm{nM}$ miR-191 mimic negative control, or $200 \mathrm{nM}$ miR-191 inhibitor, $200 \mathrm{nM}$ miR-191 inhibitor $\mathrm{NC}, 30 \mathrm{nM} \mathrm{C} / \mathrm{EBP} \beta$ small interfering RNA (siRNA) or C/EBP $\beta$ siRNA NC (scramble sequences) which were designed and synthesized by Guangzhou RiboBio Co., Ltd. (Guangzhou, China). The transfection efficiency was measured at $72 \mathrm{~h}$ post-transfection using reverse transcription-quantitative polymerase chain reaction (RT-qPCR). Transfected cells were continuously cultured for subsequent experiments. The sequences of miR-191 mimics, inhibitors and NCs were as follows: miR-191 mimics, forward 5'-CAACGGAAUCCCAAAAGCAGCUG-3' and reverse 5'-GCUGCUUUUGGGAUUCCGUUGUU-3'; NC mimics, forward 5'-UUCUCCGAACGUGUCACGUTT-3' and reverse 5'-ACGUGACACGUUCGGAGAATT-3'; miR-191-5p inhibitor, 5'-CAGCUGCUUUUGGGAUUCCGUUG-3'; NC inhibitor, 5'-CAGUACUUUUGUGUAGUACAA-3'; C/EBP $\beta$ siRNA1 forward, CCCGTGGTGTTATTTAAAGAA and reverse, 5'-UAAGCGAUUACUCAGGGCCCG-3'; C/EBP $\beta$ siRNA2 forward, 5'-AGAACGAGCGGCTGCAGAAGA-3' and reverse, 5'-AGAGGAATTCCAGTATTAGC-3'; C/EBP $\beta$ siRNA NC, forward, AATTCTCCGAACGTGTCACGT and reverse, 5'-ACGUGACACGUUCGGAGAATT-3'.

$R T-q P C R$. To detect expression of miR-191, total RNA was extracted from the tissues of patients with NSCLC or A549 cells using the mirVana miRNA isolation kit (Ambion; Thermo Fisher Scientific, Inc.) according to the manufacturer's instructions. Total RNA was subsequently transcribed into cDNA using a TaqMan MicroRNA Reverse Transcription kit (Applied Biosystems; Thermo Fisher Scientific, Inc.). RT-qPCR analysis was performed using TaqMan Advanced miRNA assays (Thermo Fisher Scientific, Inc.) according to the protocols of the manufacturer under the following thermocycling conditions: $95^{\circ} \mathrm{C}$ for $2 \mathrm{~min}$, followed by 30 cycles at $94^{\circ} \mathrm{C}$ for $45 \mathrm{sec}$, $55^{\circ} \mathrm{C}$ for $55 \mathrm{sec}, 72^{\circ} \mathrm{C}$ for $1 \mathrm{~min}$ and $72^{\circ} \mathrm{C}$ for $10 \mathrm{~min}$. To quantify the amount of $\mathrm{C} / \mathrm{EBP} \beta$ mRNA, total RNA was extracted from the tissue samples of patients with NSCLC or A549 cells at $48 \mathrm{~h}$ post-transfection using an RNeasy Mini kit (Qiagen, Inc., Valencia, CA, USA), and transcribed into cDNA using a primeScript ${ }^{\circledR} \mathrm{RT}$ reagent kit (Bio-Rad Laboratories, Inc., Hercules, CA, USA). A SYBR green qPCR assay kit (Qiagen, Inc.) was carried out to measure $\mathrm{C} / \mathrm{EBP} \beta$ expression levels. U6 and a-GAPDH were used as internal controls for miR-191 and $\mathrm{C} / \mathrm{EBP} \beta$, respectively. Samples were tested in triplicate, and the differences in threshold cycles between the target genes and house-keeping genes (U6 in miRNA and GAPDH in mRNA) were calculated using the $2^{-\Delta \Delta C q}$ method (26). The primers used were as follows: miR-191, forward 5'-AAGGGA ATCTTTCTGCACTCAAGCAT-3' and reverse 5'-ATGCTT GAGTGCAGAAAGATTCCCTT-3'; U6, forward 5'-CTCGCT TCGGCAGCACA-3' and reverse 5'-ACGCTTCACGAATTT GCGT-3'; C/EBP $\beta$, forward 5'-TTCAAGCAGCTGCCCGAG CC-3' and reverse, 5'-GCCAAGTGCCCCAGTGCCAA-3'; and GAPDH, forward 5'-GAAGGTGAAGGTCGGAGTC-3' and reverse 5'-GAAGATGGTGATGGGATTTC-3'.

Western blotting. A549 cells were transfected with miR-191 for $48 \mathrm{~h}$, as detailed above. For the immunoblotting analysis of $\mathrm{C} / \mathrm{EBP} \beta$, the cells were lysed in ice-cold lysis buffer containing a protease inhibitor cocktail (Roche Diagnostics, Basel, Switzerland), and the protein extracts were denatured in a boiling water bath for $10 \mathrm{~min}$. The concentration of protein was determined using a bicinchoninic acid kit (Thermo Fisher 
Table I. Expression of miR-191 and C/EBP $\beta$ in lung carcinoma patient tissues.

\begin{tabular}{|c|c|c|c|c|c|}
\hline Characteristic & Patients (n) & miR-191 & P-value & $\mathrm{C} / \mathrm{EBP} \beta$ & P-value \\
\hline Sex & & & 0.341 & & 0.472 \\
\hline Male & 17 & $1.744 \pm 0.094$ & & $0.666 \pm 0.039$ & \\
\hline Female & 13 & $1.605 \pm 0.109$ & & $0.627 \pm 0.034$ & \\
\hline Age (years) & & & 0.188 & & 0.230 \\
\hline$<60$ & 10 & $1.516 \pm 0.072$ & & $0.688 \pm 0.035$ & \\
\hline$\geq 60$ & 20 & $1.621 \pm 0.021$ & & $0.624 \pm 0.019$ & \\
\hline Histological grade & & & 0.005 & & 0.022 \\
\hline Well-intermediate differentiation & 18 & $1.659 \pm 0.039$ & & $0.597 \pm 0.028$ & \\
\hline Poor differentiation & 12 & $1.503 \pm 0.025$ & & $0.692 \pm 0.024$ & \\
\hline Metastasis & & & 0.013 & & $<0.001$ \\
\hline No & 17 & $1.651 \pm 0.046$ & & $0.576 \pm 0.019$ & \\
\hline Yes & 13 & $1.470 \pm 0.050$ & & $0.704 \pm 0.023$ & \\
\hline
\end{tabular}

miR-191 and C/EBP $\beta$ data are presented as the mean \pm standard deviation. Values are presented relative to adjacent normal tissues. miR, microRNA; C/EBP $\beta$, CCAAT/enhanced binding protein $\beta$.

Scientific, Inc.). Total protein $(30 \mu \mathrm{g})$ was separated by $10 \%$ SDS-PAGE and transferred to nitrocellulose membranes. Following blocking with $5 \%$ skimmed milk overnight at $4^{\circ} \mathrm{C}$, the membranes were incubated with primary antibodies against C/EBP $\beta$ (ab53138; 1:1,000) and GAPDH (ab9485; 1:1,000; both Abcam, Cambridge, MA, USA) overnight at $4^{\circ} \mathrm{C}$, followed by incubation with horseradish peroxidase-conjugated secondary antibodies (ab205718; 1:2,000; Abcam) at room temperature for $60 \mathrm{~min}$. The target protein was detected with a chemiluminescent kit (GE Healthcare Life Sciences, Little Chalfont, UK). Protein was quantitatively analyzed using Image J $1.48 \mathrm{u}$ software (National Institutes of Health, Bethesda, MD, USA).

Scratch-wound healing assay. Transfected A549 cells were cultured in 6-well plates until $90 \%$ confluence was attained. Scratches were formed by drawing two parallel lines with a $10 \mu l$ sterile pipette tip. Any cellular debris were removed by washing the cells three times with PBS. The scratched layer was then incubated in fresh media at $37^{\circ} \mathrm{C}$. The area of migration was measured at 0,12 and $24 \mathrm{~h}$ under a light microscope (magnification, $\mathrm{x} 200$ ).

Transwell invasion assay. Invasion assays were performed using a Neuro Probe Standard 24-well Chemotaxis Chamber (pore size, $8 \mu \mathrm{m}$; EMD Millipore, Billerica, MA, USA) following the manufacturer's protocol. Briefly, the filter inserts were coated with Matrigel (BD Biosciences, Franklin Lakes, NJ, USA). A total of $100 \mu \mathrm{l}$ of $3 \times 10^{5} / \mathrm{ml}$ transfected A549 cells were added into the inserts (top chamber) with serum-free medium (RPMI 1640), and the bottom chambers were coated with $1 \mathrm{ml} 10 \%$ FBS-containing media. Following $24 \mathrm{~h}$ incubation at $37^{\circ} \mathrm{C}$, non-migrated cells in the top chamber were removed and inserts were fixed in methanol at room temperature for $10 \mathrm{~min}$. The inserts were then stained with crystal violet staining solution at room temperature for $5 \mathrm{~min}$ and the cells in five randomly selected fields were counted under a light microscope (Olympus Corporation, Tokyo, Japan; magnification, x200).
Dual-luciferase reported assay. C/EBP $\beta$ was predicted to be a target gene of miR-191 based on analysis with TargetScan (http://www.targetscan.org). The 3'UTR sequence of $\mathrm{C} / \mathrm{EBP} \beta$ was amplified by PCR from genomic NSCLC cell DNA as aforementioned and then inserted into the multiple cloning site downstream of the luciferase reporter gene in the pMIR-REPORT ${ }^{\mathrm{TM}}$ luciferase plasmid (Thermo Fisher Scientific, Inc.) to construct the luciferase reporter plasmid (C/EBP $\beta$ 3'UTR wt). To generate the $\mathrm{C} / \mathrm{EBP} \beta$ 3'UTR mutated reporter (C/EBP $\beta$ 3'UTR mut), several nucleotides in the $\mathrm{C} / \mathrm{EBP} \beta$ 3'UTR that bind the seed region of miR-191 were mutated via PCR as described previously (26). All constructed plasmids were verified via DNA sequencing also as described previously (26). C/EBP $\beta$ 3'UTR wt or mut, and miR-191 or NC mimic were transfected into $293 \mathrm{~T}$ cells using Lipofectamine 2000. After $24 \mathrm{~h}$, the cells were lysed and their luciferase activities were measured using a dual-luciferase detection kit (cat. no. RG027; Beyotime Institute of Biotechnology, Haimen, China) according to the manufacturer's instructions. The levels of firefly luciferase were presented as a ratio to Renilla internal control. Primers for mutant construction were as follows: Forward, 5'-AAGGGAATCTTTCTGCACTCAAGCAT-3' and reverse 5'-ATGCTTGAGTGCAGAAAGATTCCCTT-3'.

Bioinformatics analysis. The potential targets of miR-191 were predicted by TargetScan (https://www.targetscan.org) and PicTar (http://pictar.mdc-berlin.de/). The search term used was has-miR-191.

Statistical analysis. All results were analyzed using GraphPad Prism 5 software (GraphPad Software, Inc., La Jolla, CA, USA) and the values were presented as the mean \pm standard deviation from at least three independent experiments. Statistical significance was analyzed using paired or unpaired Student's t-test. One-way Analysis of variance with Turkey's post hoc test was performed to analyze the differences among multiple groups. The clinical information of the patients was examined 
via $\chi^{2}$ test. $\mathrm{P}<0.05$ was considered to indicate a statistically significant difference.

\section{Results}

The expression of miR-191 and C/EBP $\beta$ in the tumors of patients with NSCLC. miR-191 has been reported to be highly expressed in a variety of solid cancers. RT-qPCR analysis was performed to determine the expression levels of miR-191 in human NSCLC tissues. It was demonstrated that miR-191 expression levels in tumor tissues were significantly higher than those in adjacent non-tumor control, while the expression of $\mathrm{C} / \mathrm{EBP} \beta$ was significantly downregulated (Fig. 1; $\mathrm{P}<0.01$ ). The associations between miR-191 expression and clinical characteristics were further analyzed (Table I). A significant association was observed between miR-191 expression, grade and metastasis ( $\mathrm{P}=0.005$ and 0.013 , respectively). No significant differences were observed between miR-191 expression and other clinical data, including gender and age. The results also demonstrated that there may be a strong association of miR-191 expression and NSCLC progression.

Effect of miR-191 mimics and miR-191 inhibitor on miR-191 expression in A549 cells. To further confirm the roles of miR-191 in NSCLC, cells were transfected with miR-191 mimics and miR-191 inhibitor respectively. As presented in Fig. 2A, the expression of miR-191 in the cells transfected with miR-191 mimics was significantly increased, compared with the cells transfected with miR-191 NC mimics $(\mathrm{P}<0.01)$. However, the expression levels of miR-191 were decreased following the treatment of miR-191 inhibitor in comparison with miR-191 NC inhibitor (Fig. 2B; P<0.01).

Effects of si-C/EBP $\beta$ on the expression of $C / E B P \beta$ in A549 cells. The potential roles of si-C/EBP $\beta$ in NSCLC were further explored. The results demonstrated that the mRNA level of $\mathrm{C} / \mathrm{EBP} \beta$ was significantly downregulated following the transfection of siRNA1 and siRNA2, and the siRNA1 was more potent (Fig. 3A; $\mathrm{P}<0.01$ ), which is in accordance with the protein level (Fig. 3B and $\mathrm{C} ; \mathrm{P}<0.01$ ).

miR-191 promotes NSCLC cell migration and invasion in vitro. The effects of miR-191 on the migration and invasion of A549 cells were evaluated. As measured by the scratch-wound healing assay, miR-191 mimic significantly enhanced cell monolayer restoration in A549 at $24 \mathrm{~h}$ (Fig. 4A; $\mathrm{P}<0.01$ ), while miR-191 inhibitor exhibited the opposite effect (Fig. 4B; $\mathrm{P}<0.01$ ). In accordance with these findings, miR-191 mimic significantly elevated the number of migratory cells through the Matrigel basement membrane as observed by the Transwell invasion assay at $24 \mathrm{~h}$ (Fig. 5A; $\mathrm{P}<0.01)$, whereas miR-191 inhibitor exhibited the opposite effect (Fig. 5B; $\mathrm{P}<0.01$ ). Together, these data indicated that miR-191 promotes the ability of A549 to migrate and invade in vitro.

miR-191 inhibits the expression of $C / E B P \beta$. Based on bioinformatics analyses, $\mathrm{C} / \mathrm{EBP} \beta$ was identified as a candidate target gene of miR-191. To explore the regulation of $\mathrm{C} / \mathrm{EBP} \beta$ expression mediated by miR-191, RT-qPCR and western blot
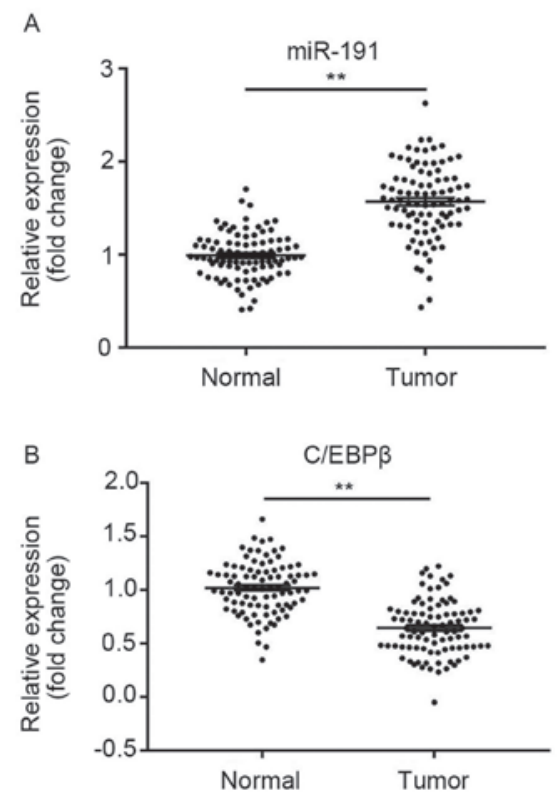

Figure 1. miR-191 and C/EBP $\beta$ expression in human NSCLC tissues (A) RT-qPCR analysis of miR-191 expression levels in NSCLC clinical tissues relative to adjacent normal control samples. Data were normalized with the expression levels of U6 control. (B) RT-qPCR analysis of C/EBP $\beta$ expression levels in NSCLC clinical tissues relative to adjacent controls. Data were normalized with the expression levels of GAPDH control. Results are expressed relative to the value of normal controls that were assigned a value of 1 . Data are presented as the mean \pm standard deviation. ${ }^{* *} \mathrm{P}<0.01$. miR, microRNA; $\mathrm{C} / \mathrm{EBP} \beta$, CCAAT/enhanced binding protein $\beta$; NSCLC, non-small cell lung carcinoma; RT-qPCR, reverse transcription-quantitative polymerase chain reaction.
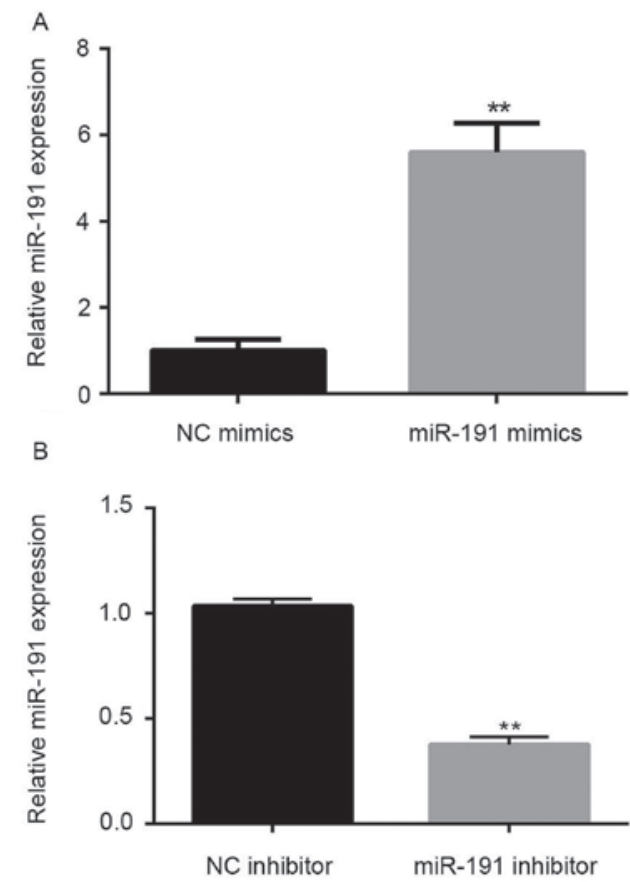

Figure 2. Transfection efficiency of miR-191 mimic and miR-191 inhibitor in A549 cells. A549 cells were transfected with miR-191 mimic, miR-191 inhibitor, miR-191 mimic NC or miR-191 inhibitor NC. (A) Expression levels of miR-191 in miR-191 mimic or miR-191 mimic NC transfected cells were detected at $72 \mathrm{~h}$ post-transfection using RT-qPCR. (B) Expression levels of miR-191 in miR-191 inhibitor or miR-191 inhibitor NC transfected cells were detected at $72 \mathrm{~h}$ post-transfection using RT-qPCR. Data are presented as the mean + standard deviation. ${ }^{* *} \mathrm{P}<0.01$ vs. NC mimic or NC inhibitor. miR, microRNA; NC, negative control; RT-qPCR, reverse transcription-quantitative polymerase chain reaction. 
A

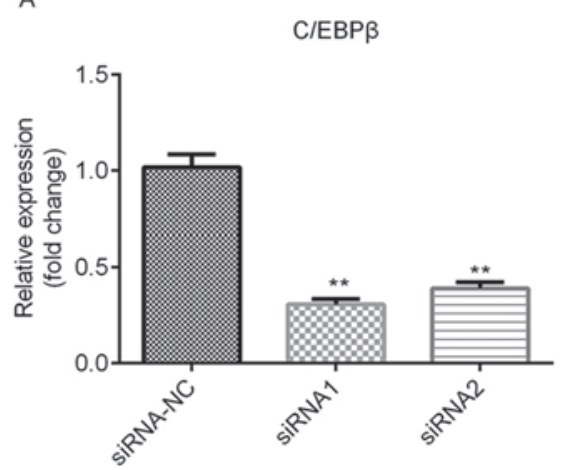

B

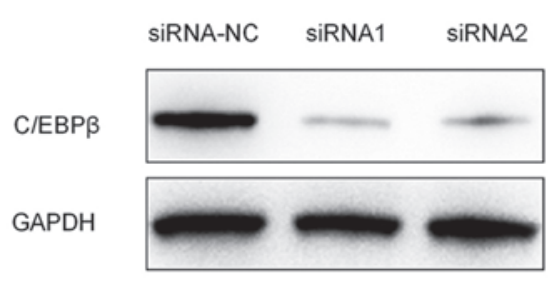

C

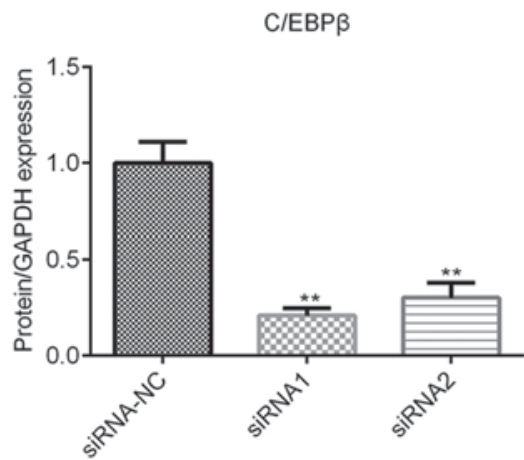

Figure 3. C/EBP $\beta$ siRNA decreased the mRNA and protein expression of C/EBP $\beta$. (A) The mRNA expression level of C/EBP $\beta$ was significantly decreased following treatment with siRNA1 and siRNA2. (B) siRNAs significantly downregulated the protein level of C/EBP $\beta$. Results were compared to the value of siRNA-NC assigned a value of 1. (C) Quantification analysis of B. Data are presented as the mean + standard deviation. ${ }^{* *} \mathrm{P}<0.01$ vs. siRNA NC. C/EBP $\beta$, CCAAT/enhanced binding protein $\beta$; siRNA, small interfering RNA; NC, negative control.

A

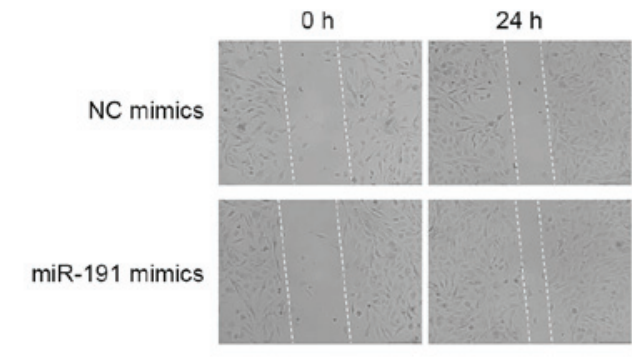

B

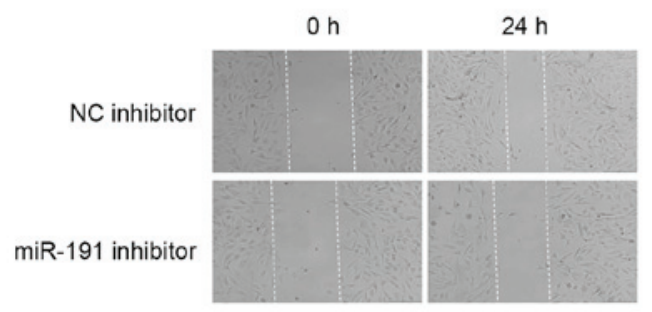

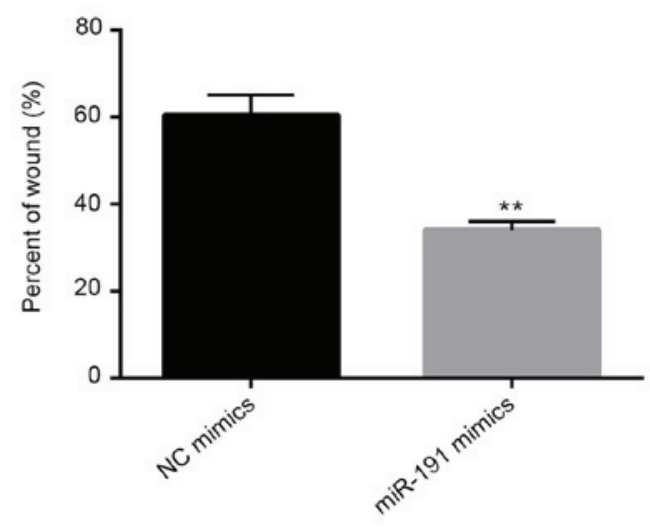

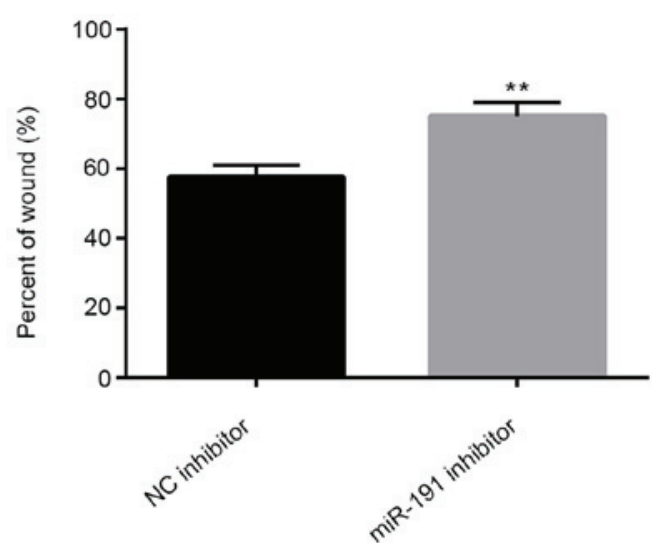

Figure 4. miR-191 enhanced the motility of A549 cells. Scratch-wound assay was performed to assess the effects of miR-191 on the migration rate of A549. (A) Effect of miR-191 mimic on the migration ability of A549 cells. (B) Effect of miR-191 inhibitor on the migration ability of A549 cells. Data are presented as the mean + standard deviation. ${ }^{* *} \mathrm{P}<0.01$ vs. NC mimic or NC inhibitor. miR, microRNA; NC, negative control.

assays were employed to detect the mRNA and protein expression levels of C/EBP $\beta$ in miR-191-transfected A549 cells. RT-qPCR analysis demonstrated that miR-191 significantly inhibited mRNA and protein expression of C/EBP $\beta$ (Fig. 6A; $\mathrm{P}<0.01)$. Conversely, miR-191 inhibitor exhibited the opposite effects (Fig. 6B; $\mathrm{P}<0.01$ ). These data suggested an inverse association between miR-191 and C/EBP $\beta$ expression levels.

$C / E B P \beta$ is the direct target of miR-191. Based on computational prediction, $\mathrm{C} / \mathrm{EBP} \beta$ has been identified to be a direct target of miR-191 (http://www.targetscan.org and http://pictar. mdc-berlin.de/). Sequence analysis revealed that $\mathrm{C} / \mathrm{EBP} \beta$ contains a putative binding site of miR-191 located in the 3'UTR (Fig. 7A). To confirm the direct interaction between miR-191 and C/EBP $\beta$, two luciferase report plasmids were constructed, C/EBP $\beta$ 3'UTR wt and C/EBP $\beta$ 3'UTR mut, and a dual luciferase reporter assay was performed. Transfection with miR-191 mimic suppressed the luciferase activity of $\mathrm{C} / \mathrm{EBP} \beta 3$ 3'UTR wt (Fig. 7B; $\mathrm{P}<0.01$ ). Mutation of four nucleotides in the predicted miR-191 binding site abolished 
A

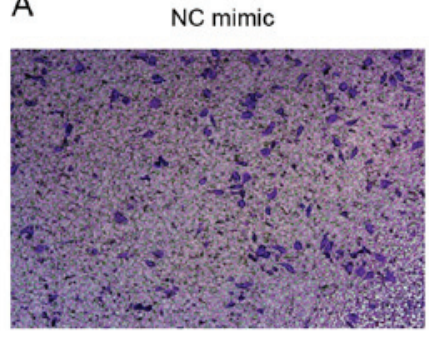

B

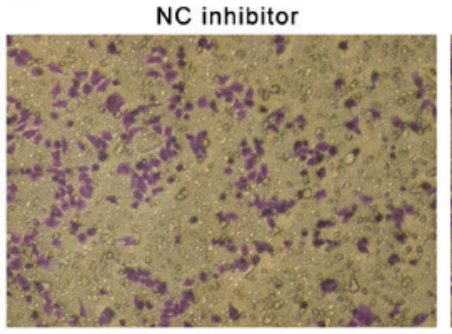

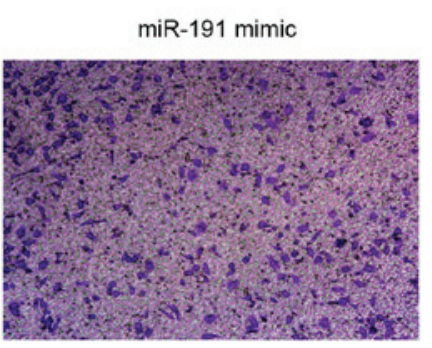
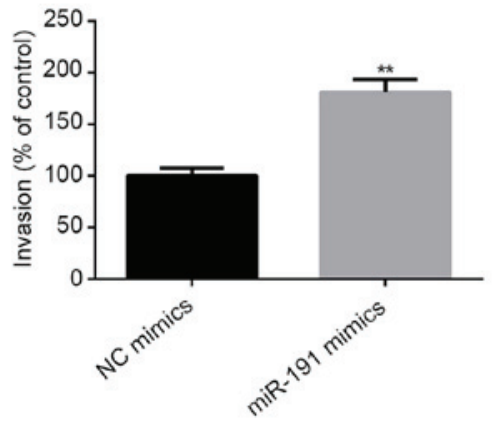

miR-191 inhibitor

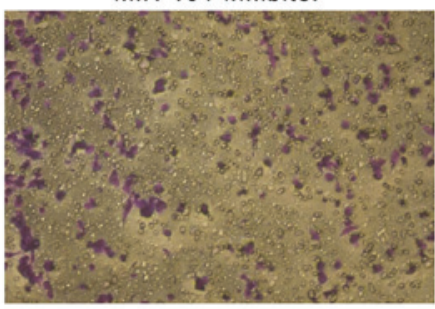

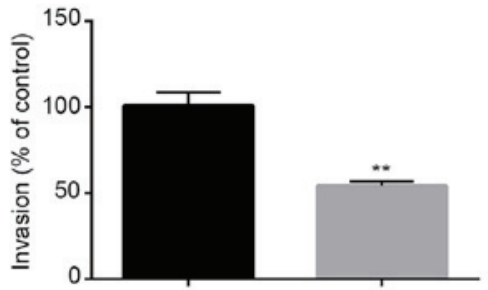

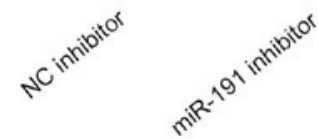

Figure 5. miR-191 promoted Transwell invasion of A549 cells. (A) Effect of miR-191 mimic on the invasion ability of A549 cells. (B) Effect of miR-191 inhibitor on the invasion ability of A549 cells (magnification, x200). Data are presented as the mean + standard deviation. ${ }^{* *} \mathrm{P}<0.01 \mathrm{vs} . \mathrm{NC}$ mimic or $\mathrm{NC}$ inhibitor. miR, microRNA; NC, negative control.

A

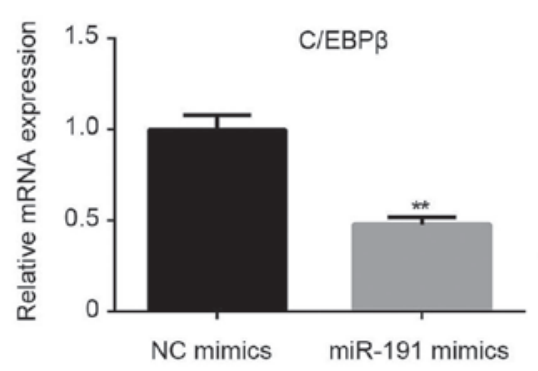

B

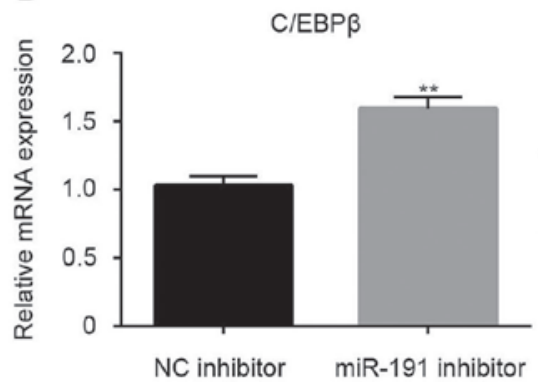

C/EBPB

GAPDH

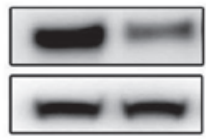

C/EBP $\beta$

GAPDH

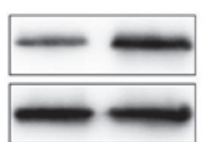

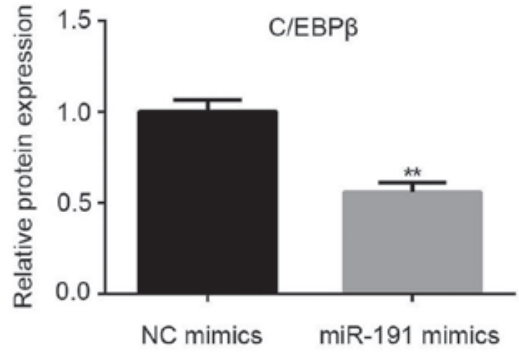

$\mathrm{C} / \mathrm{EBP} \beta$

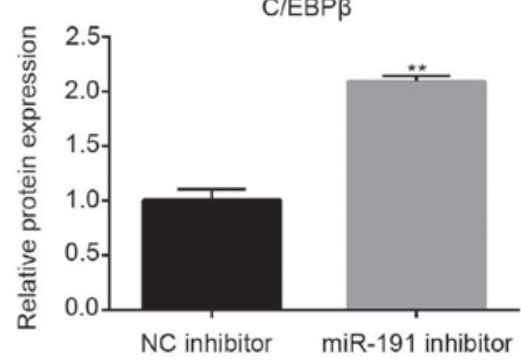

Figure 6. miR-191 suppressed mRNA and protein level of C/EBPß. (A) A549 cells were transfected with miR-191 or NC. Relative mRNA and protein expression levels of C/EBP $\beta$ were analyzed using RT-qPCR or WB. (B) A549 cells were transfected with miR-191 inhibitor or NC. Relative mRNA and protein expression levels of $\mathrm{C} / \mathrm{EBP} \beta$ were analyzed using RT-qPCR or WB. Data are presented as the mean + standard deviation of three independent experiments. ${ }^{* *} \mathrm{P}<0.01 \mathrm{vs}$. $\mathrm{NC}$ mimic or NC inhibitor. miR, microRNA; C/EBP $\beta, \mathrm{CCAAT/enhanced} \mathrm{binding} \mathrm{protein} \beta ; \mathrm{NC}$, negative control; RT-qPCR, reverse transcription-quantitative polymerase chain reaction; WB, western blotting.

the inhibitory effects of miR-191 on luciferase activity. These results provide evidence that miR-191 may have directly suppressed $\mathrm{C} / \mathrm{EBP} \beta$ translation by specifically targeting the 3'UTR of C/EBP $\beta$ mRNA.
Knockdown of C/EBP $\beta$ mimics the effect of miR-191 mimics. Finally, to determine the roles of C/EBP $\beta$ in lung cancer, A549 cells were transfected with C/EBP $\beta$ siRNA, and the migration and invasion of cells were examined. It was observed 
A

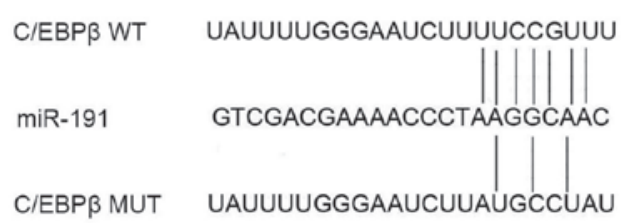

$\mathrm{B}$

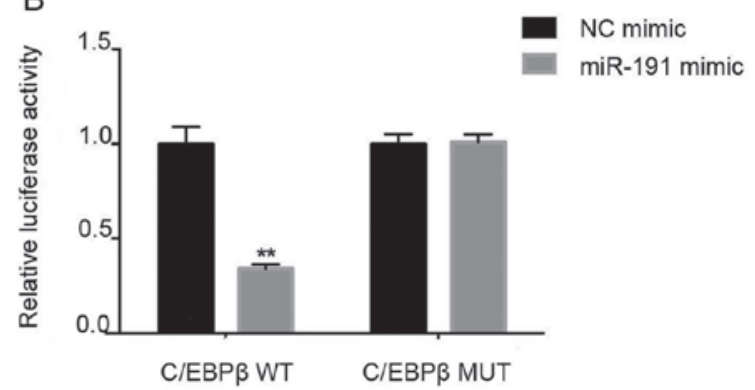

Figure 7. C/EBP $\beta$ is the direct target of miR-191. (A) Sequence alignment indicates the relative position of the miR-191 binding site in the 3 '-UTR of C/EBP $\beta$ and the mutated nucleotides are indicated. The sequences were used to construct luciferase reporter plasmids. (B) 293T cells were transfected with plasmids C/EBP $\beta$ 3'-UTR wt or mut, along with miR-191 mimic or NC. Dual luciferase assay was conducted at $24 \mathrm{~h}$ later. Luciferase activities were normalized to Renilla and presented relative to miR control (arbitrarily set at 1). Results were compared to the value of NC mimics assigned a value of 1 . Data are presented as the mean + standard deviation of three independent experiments. ${ }^{* *} \mathrm{P}<0.01$ vs. NC mimic. C/EBP $\beta$, CCAAT/enhanced binding protein $\beta$; miR, microRNA; UTR, untranslated region; wt, wild-type; mut, mutant; NC, negative control.

A

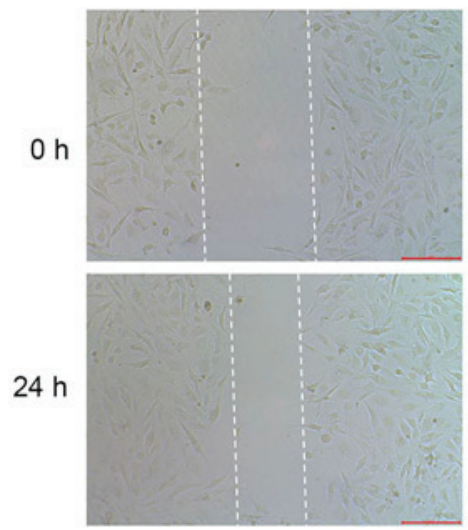

C/EBP $\beta$ SIRNA NC

B

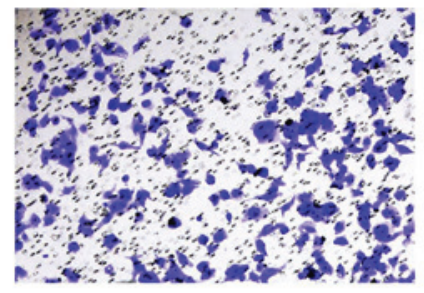

C/EBP $\beta$ SIRNA NC

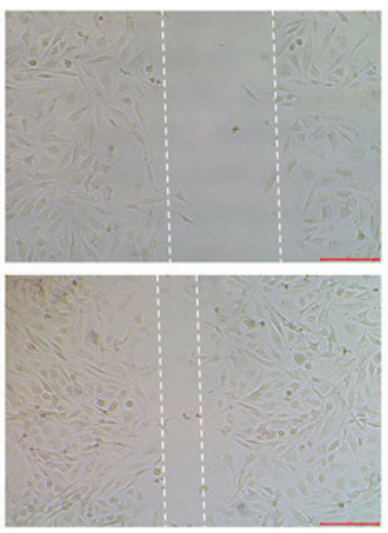

C/EBP $\beta$ SiRNA
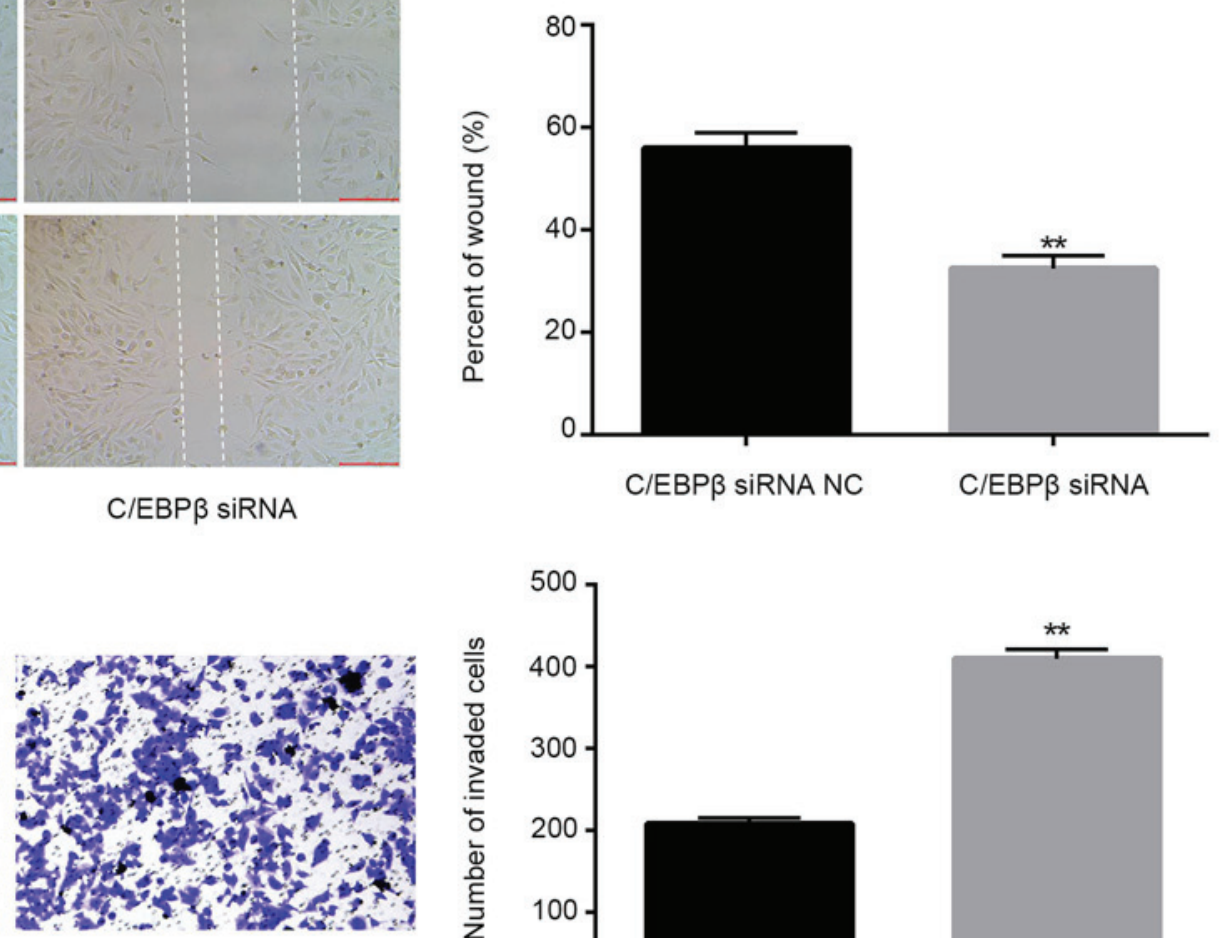

C/EBP $\beta$ SIRNA

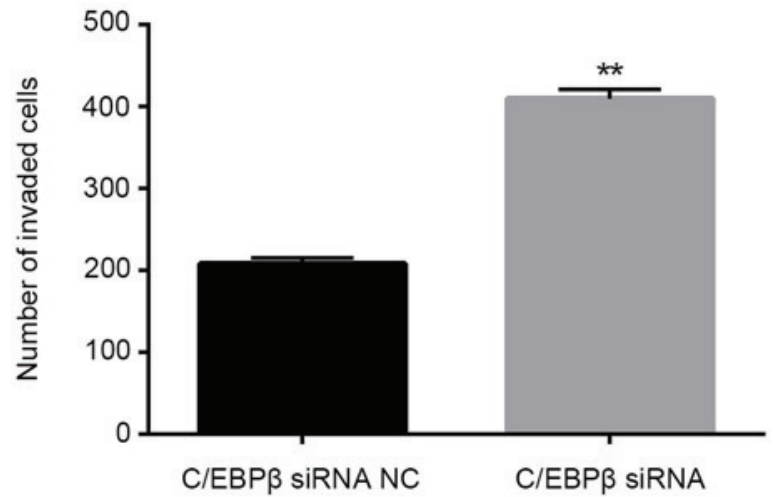

Figure 8. Effect of C/EBP $\beta$ on the migration and invasion of A549 cells. (A) Scratch-wound assay was performed to assess the effects of C/EBP $\beta$ siRNA on the migration rate A549 cells. (B) Transwell assay was performed to assess the effects of C/EBP $\beta$ siRNA on the invasion ability of A549 cells (magnification, $\mathrm{x} 200$ ). The results were compared with C/EBP $\beta$ siRNA NC. Data are presented as the mean + standard deviation of three independent experiments. ${ }^{* *} \mathrm{P}<0.01$ C/EBP $\beta$ siRNA NC. C/EBP $\beta$, CCAAT/enhanced binding protein $\beta$; siRNA, small interfering RNA; NC, negative control.

that C/EBP $\beta$ siRNA could mimic the effects of miR-191 by promoting the migration and invasion ability of A549 cells (Fig. 8A and B; $\mathrm{P}<0.01$ ).

\section{Discussion}

Aberrant expression of miRNAs is linked with multiple human cancers, indicating that miRNAs may be potential therapeutic targets or biomarkers in human cancers as they can modulate gene expression and a variety of cellular pathways (27). Dysregulation of miRNAs can disrupt tightly regulated RNA networks and thereby suppress or enhance the progression of cancer (28). In this regard, the identification of dysregulated miRNAs and their target genes may improve current knowledge of the molecular mechanisms underlying tumorigenesis. 
miR-191 has been reported to be upregulated in multiple human cancers and may promote tumor growth and metastasis $(10,11,13)$. In the present study, a significant upregulation of miR-191 was observed in NSCLC tumor samples compared with in adjacent normal tissue. Furthermore, it was observed that high expression levels of miR-191 were associated with clinical stage and metastasis in patients with NSCLC. Consistent with previous publications, these findings strongly support the potential role of miR-191 as an oncogenic gene in NSCLC. To clarify its role in NSCLC pathogenesis, in vitro functional studies were performed in the NSCLC cell line, A549. These results demonstrated that exogenous miR-191 may promote the migration and invasion of A549 cells; however, the underlying molecular mechanism of miR-191 in NSCLC remains unclear.

Bioinformatics analysis identified $\mathrm{C} / \mathrm{EBP} \beta$ as a direct target of miR-191. C/EBP $\beta$ may be involved in the regulation of normal and cancer cell proliferation. For example, enhanced expression of the C/EBP $\beta$ isoform liver-enriched inhibitory protein was observed in advanced cases of breast and ovarian cancers, and CRC $(19,20,24)$. Previously, an overall increase of in $\mathrm{C} / \mathrm{EBP} \beta$ expression was noted in squamous cell carcinoma (29). However, controversial findings have been reported in which the aberrant expression of $\mathrm{C} / \mathrm{EBP} \beta$ promoted cell death in other cancers, such as melanoma (30). The present data support certain previous findings $(30,31)$; it was observed that the transfection with miR-191 mimic induced a significant decrease in the expression of C/EBP $\beta$, and transfection of miR-191 inhibitor exhibited the opposite effects. Finally, the dual luciferase assay confirmed the direct regulation of $\mathrm{C} / \mathrm{EBP} \beta$ mediated by miR-191, and C/EBP $\beta$ siRNA can mimic the effects of miR-191.

In conclusion, the present findings demonstrated a positive association between miR-191 and NSCLC development. miR-191 may promote the migration and invasion of A549 cells in vitro partially due to the regulation of its direct target gene, $\mathrm{C} / \mathrm{EBP} \beta$. The underlying mechanisms of $\mathrm{C} / \mathrm{EBP} \beta$ promoting the invasion of A549 remain to be elucidated.

\section{Acknowledgements}

The authors would like to thank Anqiu People's Hospital for their supervision of the current study (Anqiu, China).

\section{Funding}

No funding was received.

\section{Availability of data and materials}

The datasets used and/or analyzed during the present study are available from the corresponding author on reasonable request.

\section{Authors' contributions}

FL, JW and JS performed the experiments; FL, YW and FY collected materials and interpreted the data; CL deigned and approved the current study. All authors read and approved the final manuscript.

\section{Ethics approval and consent to participate}

Written informed consent was obtained from all patients and all study protocols were approved by the local ethics committee of Anqiu People's Hospital (Anqiu, China).

\section{Patient consent for publication}

Written informed consent was obtained from all patients.

\section{Competing interests}

The authors declare that they have no competing interests.

\section{References}

1. Cui LH, Xu HR, Yang W and Yu LJ: IncRNA PCAT6 promotes non-small cell lung cancer cell proliferation, migration and invasion through regulating miR-330-5p. Onco Targets Ther 11: 7715-7724, 2018

2. Li J and Wei L: Increased expression of LINC01510 predicts poor prognosis and promotes malignant progression in human non-small cell lung cancer. Biomed Pharmacother 109: 519-529, 2019.

3. Wang B, Lv K, Chen W, Zhao J, Luo J, Wu J,LiZ, Qin H, Wong TS Yang W, et al: miR-375 and miR-205 regulate the invasion and migration of laryngeal squamous cell carcinoma synergistically via AKT-mediated EMT. Biomed Res Int 2016: 9652789, 2016.

4. Bartel DP: MicroRNAs: Genomics, biogenesis, mechanism, and function. Cell 116: 281-297, 2004.

5. He L and Hannon GJ: MicroRNAs: Small RNAs with a big role in gene regulation. Nat Rev Genet 5: 522-531, 2004.

6. Lages E, Ipas H, Guttin A, Nesr H, Berger F and Issartel JP: MicroRNAs: Molecular features and role in cancer. Front Biosci (Landmark Ed) 17: 2508-2540, 2012.

7. Calin GA and Croce CM: MicroRNA signatures in human cancers. Nat Rev Cancer 6: 857-866, 2006.

8. Nagpal N, Ahmad HM, Molparia B and Kulshreshtha R: MicroRNA-191, an estrogen-responsive microRNA, functions as an oncogenic regulator in human breast cancer. Carcinogenesis 34: 1889-1899, 2013.

9. Shi X, Su S, Long J, Mei B and Chen Y: MicroRNA-191 targets $\mathrm{N}$-deacetylase/N-sulfotransferase 1 and promotes cell growth in human gastric carcinoma cell line MGC803. Acta Biochim Biophys Sin (Shanghai) 43: 849-856, 2011.

10. Liu H, Xu XF, Zhao Y, Tang MC, Zhou YQ, Lu J and Gao FH: MicroRNA-191 promotes pancreatic cancer progression by targeting USP10. Tumour Biol 35: 12157-12163, 2014.

11. Elyakim E, Sitbon E, Faerman A, Tabak S, Montia E, Belanis L, Dov A, Marcusson EG, Bennett CF, Chajut A, et al: hsa-miR-191 is a candidate oncogene target for hepatocellular carcinoma therapy. Cancer Res 70: 8077-8087, 2010.

12. Qin S,Zhu Y,AiF,Li Y,Bai B, Yao W and Dong L: MicroRNA-191 correlates with poor prognosis of colorectal carcinoma and plays multiple roles by targeting tissue inhibitor of metalloprotease 3 . Neoplasma 61: 27-34, 2014.

13. Li H, Zhou ZQ, Yang ZR, Tong DN, Guan J, Shi BJ, Nie J, Ding XT, Li B, Zhou GW and Zhang ZY: MicroRNA-191 acts as a tumor promoter by modulating the TET1-p53 pathway in intrahepatic cholangiocarcinoma. Hepatology 66: 136-151, 2017.

14. Cruz-Munoz W and Khokha R: The role of tissue inhibitors of metalloproteinases in tumorigenesis and metastasis. Crit Rev Clin Lab Sci 45: 291-338, 2008.

15. Robinson GW, Johnson PF, Hennighausen L and Sterneck E: The $\mathrm{C} / \mathrm{EBPbeta}$ transcription factor regulates epithelial cell proliferation and differentiation in the mammary gland. Genes Dev 12: 1907-1916, 1998.

16. Seagroves TN, Krnacik S, Raught B, Gay J, Burgess-Beusse B, Darlington GJ and Rosen JM: C/EBPbeta, but not C/EBPalpha, is essential for ductal morphogenesis, lobuloalveolar proliferation, and functional differentiation in the mouse mammary gland. Genes Dev 12: 1917-1928, 1998.

17. Smink JJ, Bégay V, Schoenmaker T, Sterneck E, de Vries TJ and Leutz A: Transcription factor C/EBPbeta isoform ratio regulates osteoclastogenesis through MafB. EMBO J 28: 1769-1781, 2009. 
18. Wethmar K, Bégay V, Smink JJ, Zaragoza K, Wiesenthal V, Dörken B, Calkhoven CF and Leutz A: C/EBPbetaDeltauORF mice-a genetic model for uORF-mediated translational control in mammals. Genes Dev 24: 15-20, 2010.

19. Zhang XF, Li KK, Gao L, Li SZ, Chen K, Zhang JB, Wang D, Tu RF, Zhang JX, Tao KX, et al: miR-191 promotes tumorigenesis of human colorectal cancer through targeting C/EBP $\beta$. Oncotarget 6: 4144-4158, 2015.

20. Sundfeldt K, Ivarsson K, Carlsson M, Enerbäck S, Janson PO, Brännström M and Hedin L: The expression of CCAAT/enhancer binding protein $(\mathrm{C} / \mathrm{EBP})$ in the human ovary in vivo: Specific increase in $\mathrm{C} / \mathrm{EBPbeta}$ during epithelial tumour progression. $\mathrm{Br}$ J Cancer 79: 1240-1248, 1999.

21. Barakat DJ, Zhang J, Barberi T, Denmeade SR, Friedman AD and Paz-Priel I: CCAAT/Enhancer binding protein $\beta$ controls androgen-deprivation-induced senescence in prostate cancer cells. Oncogene 34: 5912-5922, 2015.

22. Aguilar-Morante D, Morales-Garcia JA, Santos A and Perez-Castillo A: CCAAT/enhancer binding protein $\beta$ induces motility and invasion of glioblastoma cells through transcriptional regulation of the calcium binding protein S100A4. Oncotarget 6: 4369-4384, 2015.

23. Gomis RR, Alarcón C, Nadal C, Van Poznak C and Massagué J: $\mathrm{C} / \mathrm{EBPbeta}$ at the core of the TGFbeta cytostatic response and its evasion in metastatic breast cancer cells. Cancer Cell 10 203-214, 2006.

24. Park BH, Kook S, Lee S, Jeong JH, Brufsky A and Lee BC: An isoform of $\mathrm{C} / \mathrm{EBP} \beta$, LIP, regulates expression of the chemokine receptor CXCR4 and modulates breast cancer cell migration. J Biol Chem 288: 28656-28667, 2013.

25. Fang T, Cui M, Sun J, Ge C, Zhao F, Zhang L, Tian H, Zhang L, Chen T, Jiang G, et al: Orosomucoid 2 inhibits tumor metastasis and is upregulated by CCAAT/enhancer binding protein $\beta$ in hepatocellular carcinomas. Oncotarget 6: 16106-16119, 2015.
26. Livak KJ and Schmittgen TD: Analysis of relative gene expression data using real-time quantitative PCR and the 2(-Delta Delta C(T)) method. Methods 25: 402-408, 2001

27. Lin SS, Peng CY, Liao YW, Chou MY, Hsieh PL and Yu CC: miR-1246 targets CCNG2 to enhance cancer stemness and chemoresistance in oral carcinomas. Cancers (Basel) 10: pii: E272, 2018

28. Chen M, Wu L, Tu J, Zhao Z, Fan X, Mao J, Weng Q, Wu X, Huang L, Xu M and Ji J: miR-590-5p suppresses hepatocellular carcinoma chemoresistance by targeting YAP1 expression. EBioMedicine 35: 142-154, 2018.

29. Anand S, Ebner J, Warren CB, Raam MS, Piliang M, Billings SD and Maytin EV: C/EBP transcription factors in human squamous cell carcinoma: Selective changes in expression of isoforms correlate with the neoplastic state. PLoS One 9: e112073, 2014.

30. Yang X, Du T, Wang X, Zhang Y, Hu W, Du X, Miao L and Han C: IDH1, a CHOP and C/EBP $\beta$-responsive gene under ER stress, sensitizes human melanoma cells to hypoxia-induced apoptosis. Cancer Lett 365: 201-210, 2015.

31. Yan Y, Hanse EA, Stedman K, Benson JM, Lowman XH, Subramanian S and Kelekar A: Transcription factor C/EBP- $\beta$ induces tumor-suppressor phosphatase PHLPP2 through repression of the miR-17-92 cluster in differentiating AML cells. Cell Death Differ 23: 1232-1242, 2016.

c) (i) $\Theta$ This work is licensed under a Creative Commons EY NO ND Attribution-NonCommercial-NoDerivatives 4.0 International (CC BY-NC-ND 4.0) License. 